\title{
The Lebanese-Syrian crisis: impact of influx of Syrian refugees to an already weak state
}

This article was published in the following Dove Press journal:

Risk Management and Healthcare Policy

I 4 July 2016

Number of times this article has been viewed

\section{Zeinab Cherri \\ Pedro Arcos González \\ Rafael Castro Delgado \\ Unit for Research in Emergency and Disaster, Department of Medicine, University of Oviedo, Oviedo, Asturias, Spain}

Background: Lebanon, a small Middle Eastern country facing constant political and national unity challenges with a population of approximately 300,000 Palestinian and Iraqi refugees, has welcomed more than 1.2 million Office of the United Nations Commissioner for Refugees (UNHCR)-registered Syrian refugees since 2012. The Government of Lebanon considers individuals who crossed Lebanese-Syrian borders since 2011 as "displaced", emphasizing its long-standing position that Lebanon is not a state for refugees, refusing to establish camps, and adopting a policy paper to reduce their numbers in October 2014. Humanitarian response to the Syrian influx to Lebanon has been constantly assembling with the UNHCR as the main acting body and the Lebanon Crisis Response Plan as the latest plan for 2016.

Methods: Review of secondary data from gray literature and reports focusing on the influx of Syrian refugees to Lebanon by visiting databases covering humanitarian response in complex emergencies. Limitations include obtaining majority of the data from gray literature and changing statistics due to the instability of the situation.

Results: The influx of Syrian refugees to Lebanon, an already weak and vulnerable state, has negatively impacted life in Lebanon on different levels including increasing demographics, regressing economy, exhausting social services, complicating politics, and decreasing security as well as worsened the life of displaced Syrians themselves.

Conclusion: Displaced Syrians and Lebanese people share aggravating hardships of a mutual and precarious crisis resulting from the Syrian influx to Lebanon. Although a lot of response has been initiated, both populations still lack much of their basic needs due to lack of funding and nonsustainable program initiatives. The two major recommendations for future interventions are to ensure continuous and effective monitoring and sustainability in order to alleviate current and future suffering in Lebanon.

Keywords: Syria, refugees, Lebanon, impact, risk factors, vulnerability

\section{Introduction}

Lebanon, a small country with a surface area of $10,452 \mathrm{~km}^{2}$ and a mountainous nature, is located on the east of the Mediterranean Sea in western Asia and bounded by Syria in the north and the east and Palestine in the south. Since it is located in a water-deficient region, Lebanon's most valuable natural resource is water; yet, it is substantially lost due to suboptimal management. Lebanon was founded in September 1920 and the Lebanese constitution was written in 1926 declaring it as a free economy, parliamentary democracy, and secular Arab state. Amended after the independence in 1943 and revisited in 1990 through the Ta'if Accord, the constitution acknowledges the rights of each religious community, but demands the eventual elimination of political confessionalism, officially recognizing over
Correspondence: Pedro Arcos González Unidad de Investigación en Emergencia y Desastre, Facultad de Medicina, Campus del Cristo 33003, Oviedo, España

Tel+34630549728

Email arcos@uniovi.es 
18 religious sects. ${ }^{1,2}$ Approximately, 4.467 million is the total estimated population, ${ }^{3}$ but no precise numbers on the population distribution per sect are present, since the only population census that was performed was when Lebanon was still under the French mandate in 1932. More than 220,000 Palestinians live in refugee camps and $\sim 40,000$ Iraqi refugees as well as an additional 100,000 workers including domestic workers and semi-skilled workers, majorly from Egypt, African, and South East Asian countries, reside in the country. ${ }^{2}$ While Lebanon's demographic and confessional diversity is considered a national resource, it also represents significant challenges to political and national unity during a period of regional unrest. The hardness in establishing a new government and reconciling on a new electoral law exhibit the magnitude of political polarization. ${ }^{1}$

This paper examines the relationship between the vulnerable factors already prevalent in Lebanon and their role in further aggravating the Syrian refugee influx for both the Lebanese and displaced Syrians.

\section{Methods}

Secondary data sources focusing on the influx of Syrian refugees to Lebanon and the response initiated were reviewed. Visited databases included Office for the Coordination of Humanitarian Affairs, PreventionWeb, ReliefWeb, United Nations Development Project, Office of the United Nations Commissioner for Refugees (UNHCR), and the World Health Organization (WHO). The data, statistics, and plans about Syrian refugees in Lebanon were obtained from international sources dealing with humanitarian response in complex emergencies, mainly ReliefWeb and UNHCR using the names of countries (Lebanon, Syria) as the research criteria and narrowing the search for reports and relevant data about this crisis. This paper includes vulnerabilities and negative impacts of the Syrian refugee influx in Lebanon summarized from the various reports and articles obtained. All the data were first collected in a folder. Then, they were processed and reviewed to present the relevant information in written format with related figures.

\section{Results \\ Lebanon and Syrian refugees}

With respect to the 1951 Convention relating to the Status of Refugees and its 1967 Protocol, Lebanon is neither a State Party nor it has signed its protocol; 4,5 however, voluntarily executing some of its articles and considering granting the status of refugee to individuals is within its boundary of free choice. The Lebanese Government emphasizes on all instances its longestablished stance confirming that Lebanon is not an ultimate destination for refugees, an asylum country, or a resettlement country deeming individuals who have fled from Syrian borders to Lebanese borders beyond March 2011 as "displaced". 5

Lebanon welcomed more than 1.2 million Syrian refugees registered with UNHCR from 2012 till the end of 2015 (Figure 1), ${ }^{5,6}$ and many more are present but without registration. ${ }^{7}$ As the Lebanese Government has not permitted the establishment of formal camps, displaced Syrians remain dispersed all over the country in over 1,700 localities ${ }^{8}$ all over the six districts, where Bekaa (Arsal) and North (Akkar), which include the most vulnerable, poor, and undeserved communities, ${ }^{9}$ host the largest numbers $(373,124)$ followed by Beirut $(314,731) .{ }^{10}$ In spite of its contemporary history of military and political conflicts as well as pressures on its infrastructure, Lebanon kept its borders open till October 2014,,$^{71,12}$ after which it adopted a policy

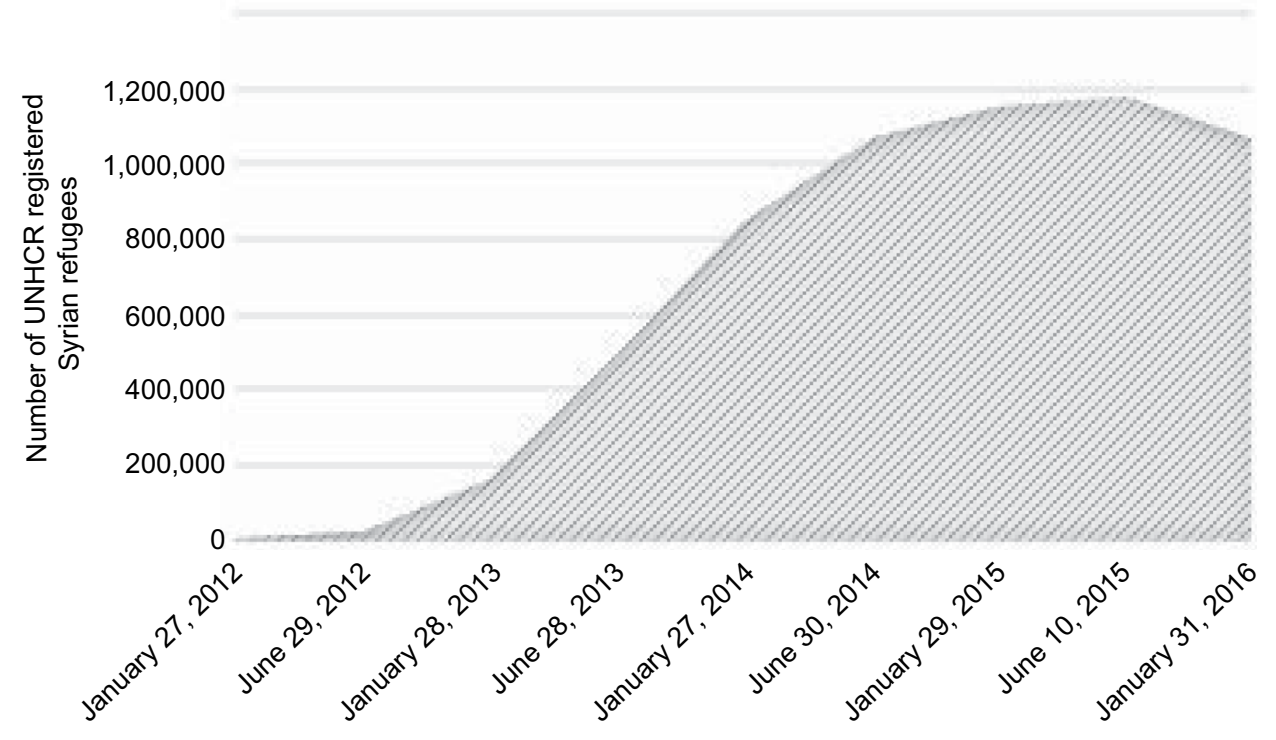

Figure I UNHCR registered Syrian refugees in Lebanon since January 2012. Abbreviation: UNHCR, United Nations High Commissioner for Refugees. 
paper to limit and decrease the Syrian refugee population on the Lebanese land, secure Lebanese and Syrian people's safety, and ease the burden placed on Lebanese people and economy. ${ }^{13}$ Moreover, Lebanon is now considered the highest per capita embracer of refugees in the world, ${ }^{7,12}$ and it is anticipated that the number of Syrian refugees in Lebanon will reach 1.5 million by the end of $2015 .^{7}$ Figure 1 shows the evolution of the total number of refugees from 2012 to the present. ${ }^{14}$

\section{Response to Syrian influx in Lebanon}

Since the beginning of the conflict in Syria, momentum to respond to the collective social, humanitarian, economic, and environmental shocks in Lebanon has been regularly assembling. In 2014, on the humanitarian part, the Regional Response Plan and two-sided humanitarian programs in collaboration with the Government, national and international nongovernmental organizations, and the United Nations (UN) provided more than US\$770 million to ease stress on Lebanese poor, Lebanese returnees, displaced Syrians, and Palestine refugees from Syria and Lebanon. In addition, the international community has also devoted considerable financial resources to infrastructure and initiatives for policy reforms tailored to address the development hurdles existing before the crisis. ${ }^{5}$ Moreover, UNHCR is one of the main bodies acting for this purpose in Lebanon, and a sector analysis of its administered humanitarian assistance is summarized in Figure 2. ${ }^{8}$

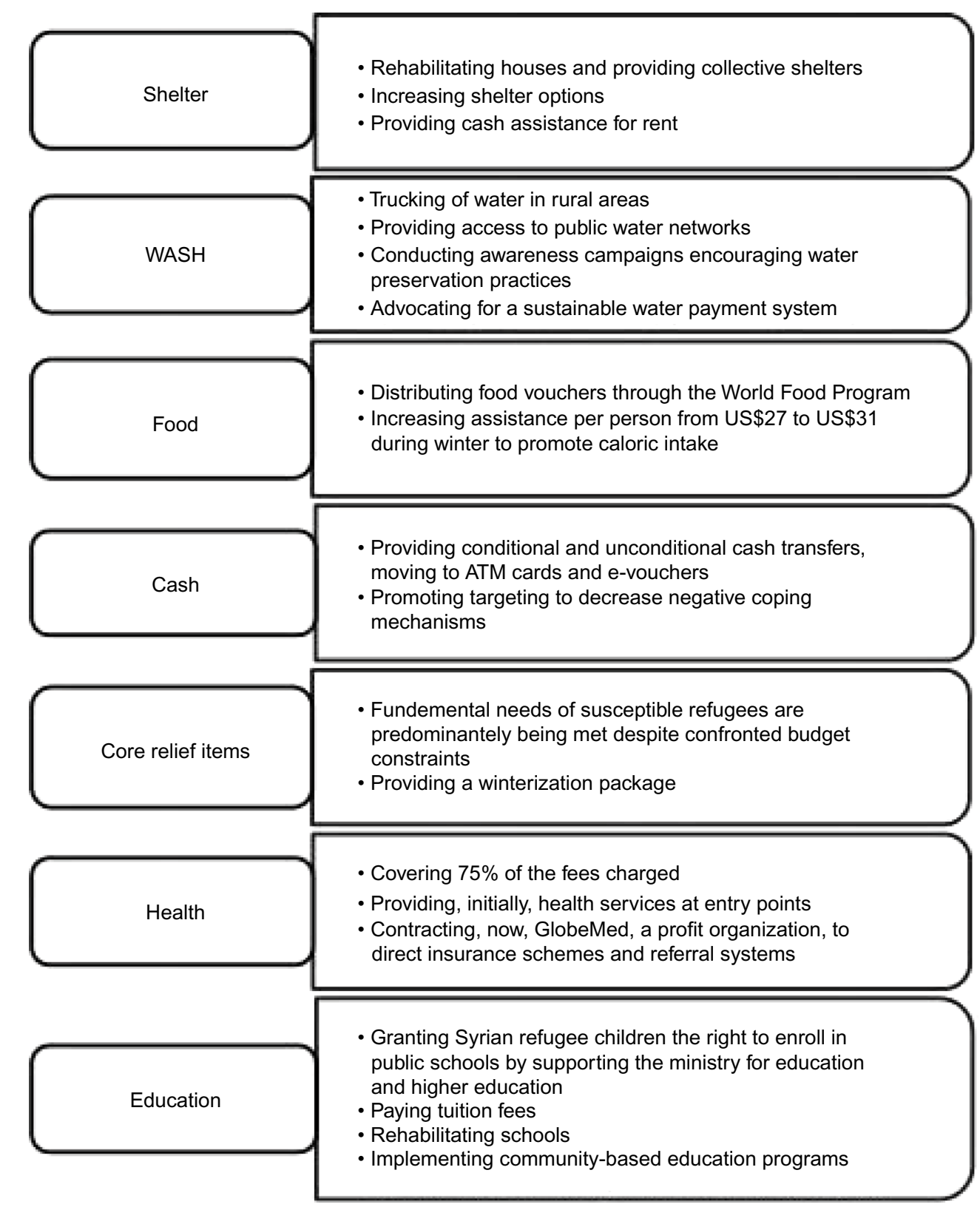

Figure 2 Sector analysis of humanitarian assistance by administered UNHCR.

Abbreviations: ATM, automated teller machine; UNHCR, United Nations High Commissioner for Refugees; WASH, water, hygiene, and sanitation. 


\section{The 2015-2016 Lebanon crisis response}

The Regional Refugee and Resilience Plan 2015-2016, referred to as the 3RP, includes the Lebanon Crisis Response Plan (LCRP) as the response to the Syrian influx in Lebanon. The LCRP is managed by UNCHR and the United Nations Development Project. Initiated by the Lebanese Government and the UN in 2015, the LCRP merges a focused humanitarian response with a larger plan in order to boost stabilization in Lebanon, benefiting from lessons learned by the various national and international partners. It attempts to raise US\$2.14 billion to supply protection and humanitarian assistance to 2.2 million de facto Syrian refugees who are highly vulnerable and have acute needs, and invest in institutions, services, and economies to reach 2.9 million vulnerable people. ${ }^{5}$

The LCRP has three strategic priorities or response areas which address the capacities of affected communities, national government, and Lebanese institutions to improve quality of public services to poor Lebanese and de facto Syrian refugees and help them cope with worst effects due to poverty and displacement while decreasing tensions in highly stressed communities. The three response strategies work on nine sectors including basic assistance; food security; shelter; education; water, hygiene, and sanitation (WASH); livelihoods; health; social stability; and protection. ${ }^{5}$ A summary of these sectors is presented in Table 1. Except for WASH, the majority of the sectors are massively underfunded, ${ }^{5}$ forcing the UN to decrease its coverage for shelter, health, and nutrition. ${ }^{15}$

\section{Effect of emergency on Lebanon}

In 2011, when Lebanon initially opened its frontiers to Syrian families fleeing the conflict, communities of Lebanon complied with no hesitation. They supplied shelter, generous welcome, services, and support despite the fact that their own needs, in numerous instances, were already elevated. Today, after 4 years, with no anticipated termination of vehemence in Syria, the Government and Lebanese communities have arrived at a critical point and a stringent stability test on the social and economic impact of the Syrian crisis in Lebanon attained new peaks. ${ }^{5}$

\section{Demographic impact}

By April 2014, the millionth Syrian refugee was registered with UNHCR in Lebanon. In November, Lebanon had welcomed more than 1.5 million people escaping the conflict in Syria with 440,000 new comers in 2014 alone. Aside from the Government's estimate of hundreds of thousands of unregistered individuals, ${ }^{5}$ after December 2014 in Lebanon, more than one in each four people is a de facto Syrian refugee or a Palestinian refugee. ${ }^{4,5}$ The number of people living in Lebanon - currently having 1,421 informal settlements - has sharply soared by a minimum of 30\% since March 2011 possibly by nearly 1.5 million as reported by Government estimates - in a state of only four million Lebanese. In addition, urban densification is anticipated to rise by one-third with a population density increasing from 400 to 520 persons per square kilometer. ${ }^{5}$

\section{Economic impact}

The Syrian refugee influx in Lebanon has aggravated political, economic, and security challenges, impairing major drivers of economy, such as trade, banking, and tourism, ${ }^{1}$ and decreasing job opportunities as well as increasing the challenges of attaining the key Millennium Development Goals. Growth of the economy has tumbled with debt augmenting

Table I Sector plans of the LCRP

\begin{tabular}{lllllll}
\hline Sector & $\begin{array}{l}\text { People in } \\
\text { need }\end{array}$ & $\begin{array}{l}\text { People } \\
\text { targeted }\end{array}$ & $\begin{array}{l}\text { Requirements } \\
\text { (million US\$) }\end{array}$ & $\begin{array}{l}\text { Number of } \\
\text { partners }\end{array}$ & $\begin{array}{l}\text { Funding already received, } \\
\text { 2015 (million US\$) }\end{array}$ & $\begin{array}{l}\text { Estimated needs } \\
\text { 2016 (million US\$) }\end{array}$ \\
\hline Food security & $\mathrm{I}, 520,000$ & $\mathrm{I}, 236,976$ & 447 & 13 & 5.9 & 343.7 \\
Basic assistance & $\mathrm{I}, 34 \mathrm{I}, 240$ & 889,500 & 288.6 & 29 & 1.5 & 263 \\
Education & 750,000 & 377,000 & 263.6 & 28 & 100 & 255 \\
Health & $3,322,000$ & $2,040,000$ & 249.2 & 24 & 20.3 & 198.6 \\
WASH & $3,365,000$ & $2,862,29 \mid$ & 231.4 & 33 & 204.3 & 190 \\
Livelihoods & 700,000 & 242,536 & 175.9 & 27 & 17.7 & 175 \\
Social stability & $242^{\mathrm{a}}$ & $242^{\mathrm{b}}$ & 157.3 & 27 & 18 & 160 \\
Shelter & $\mathrm{I}, 806,200$ & $\mathrm{I}, 368,255$ & 147.2 & 23 & 5 & 150 \\
Protection & $3,365,000$ & $2,185,000$ & 183 & 33 & 16.3 & 171.3 \\
\hline
\end{tabular}

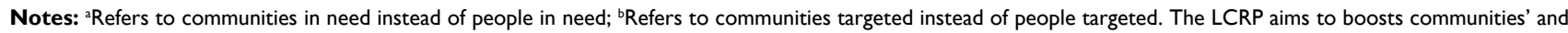
institutions' abilities to prevent conflict, alleviate tensions, and report the comprehensive response on the progress of tension. Adapted from Lebanon crisis response plan 2015-2016.

Abbreviations: LCRP, Lebanon Crisis Response Plan; WASH, water, hygiene, and sanitation. 
to $141 \%$ of growth domestic product (GDP) in $2013^{5}$ and GDP growth decreasing from $10 \%$ in 2010 to $1 \%$ in $2014,{ }^{7}$ and it is expected to increase just by $2 \%$ in 2015.5 Now, one in five Lebanese are unemployed ${ }^{5}$ with unemployment doubling to $34 \% \%^{5,7}$ and peaking at record rates as the labor force has increased by $50 \%$ since 2011 , and one-third of young Lebanese laborers are unable to find work competing in a particularly intensified informal sector that contributes to more than $56 \%$ of total employment. It has become more difficult to even acquire jobs with low salaries, dramatically impacting labor market standards. ${ }^{5}$ These factors have exhausted public spending and have tested Lebanon's economic, social, and political resilience. ${ }^{7}$ Furthermore, since 2011, Government and World Bank estimates reveal that the number of poor people presently living in Lebanon has increased by 170,000 - approximately a two-third fold reaching 2.1 million; of which, 336,000 are living with less than US\$2.4 per day, which is under Lebanon's lowest poverty line. ${ }^{5}$ Moreover, the rising demand and restricted supply of accommodation are contributing to soaring rental prices affecting poor Lebanese who are unable to cope with this rise, ${ }^{8}$ whereby a $44 \%$ increase in rents was reported between June 2012 and June 2013. ${ }^{16}$

\section{Social services impact}

After 4 years of restricted access to fundamental services and economic anguish, youth and children are the ones mostly affected, being $\sim 50 \%$ of the affected population, as a minimum of 1.2 million are presently growing up deprived, susceptible, and with severe needs for protection and basic services. Public services are exhausted, including infrastructure, national health, ${ }^{5,11}$ and education, and are left unable to handle the additional magnitudes. The impact has mostly been evident in the health care system, ${ }^{12,17}$ witnessing a 27\% increase in tuberculosis rates since $2011,,^{15,17}$ currently struggling and lacking staff, equipment, ${ }^{12}$ and medication. ${ }^{9,12}$ Consequently, Lebanese have had decreased access to primary health care because of perceived reduced quality of care, overcrowding, and increased waiting time. ${ }^{9}$ On the other hand, most Lebanese children are enrolled in private schools, while only 300,000 or $27 \%$ attend public ones. Research published in 2014 by the Ministry of Environment traced the range of damage to the already fragile environment in Lebanon. It indicated that municipal spending on waste disposal, particularly in Akkar and Bekaa, has increased by $40 \%$, and $92 \%$ of sewage is running untreated into water sources due to the increased demand for land, water resources, electricity, and waste disposal, exceeding the capacity to meet it. As a result, since 2011 , waste water pollution has increased by $33 \%{ }^{5}$

\section{Political and security impact}

Lebanon is solicitous to conserve its ephemeral stability with rapidly aggravating social tensions and poverty in regions of Lebanon where huge numbers of registered Syrian refugees coexist with a history of fragile delivery of service for the local population. ${ }^{5}$ In a 2013 national poll addressing Lebanese perceptions toward the Syrian crisis, $52 \%$ of the interviewees believed that displaced Syrians are threatening national stability and security, a solid $98 \%$ presumed Syrian refugees are taking jobs from the local population, and $\sim 50 \%$ thought that the refugees are benefiting from financial aid in an unfair manner. ${ }^{18}$ Amounting security concerns are affecting all susceptible people. In 2014, the prospect perils of having a relapsing condition were confirmed when radical armed groups associated with the claimed-to-be "Islamic State" and Al-Nusra Front arrived to Lebanon to displace its communities, assault Lebanese Armed Forces, and heighten worries around national stability. A series of security accidents led to the engagement of the Lebanese Armed Forces with these groups. ${ }^{5}$

Of the countries affected by the influx, Lebanon has been the mostly affected in terms of political and security environment as the country has been divided into two groups: those who support the opposition in Syria and those who support Assad. ${ }^{16}$ As a result, a series of 29 suicide bombings and assassinations occurred between October 2012 and November 2015 leading to the death of 205 individuals and injuring 1,796 others; the vast majority of victims were civilians. ${ }^{19}$ A summary of these events is presented in Table 2.

\section{Impact on displaced Syrians in Lebanon}

De facto refugees are confronting a prolonged test of endurance and bravery as they deplete their savings during a 4-year period of restricted access to services, economic hardship, and heightening vulnerability. At the end of 2014, 90\% of Syrians fled the border requiring help to register, find food and shelter, and attain basic material needs. At least 78\% of those registered were women and children. An estimated $30 \%$ do not have documentation for legal stay, and $29 \%$ cannot meet their survival needs with no access to community support networks - their number is expected to reach 435,000 by the end of 2015 . On the other hand, $55 \%$ of the registered Syrians have more than US\$400 as debt with $82 \%$ paying rent ${ }^{5}$ averaging US\$200 per month for a low standard room. ${ }^{8}$ The International Labor Organizations estimates that while $50 \%$ of young Syrians do not have activities to generate income, the percentage increases to $66 \%$ among young 
Table 2 Summary of attacks in Lebanon post-Syrian conflict

\begin{tabular}{|c|c|c|c|c|c|}
\hline Date & Area & Target & Method & Death & Injured \\
\hline Oct 19, 2012 & Achrafieh, West Beirut & $\begin{array}{l}\text { Wissam Al Hassan, head of the intelligence } \\
\text { branch of the ISF }\end{array}$ & Massive car bomb & 8 & 128 \\
\hline July 9,2013 & Beir el-Abed, South Beirut & Popular street associated with Hezbollah & Car bomb & 0 & 50 \\
\hline Aug 15,2013 & Roueiss, South Beirut & Hezbollah stronghold & Car bomb & 27 & 300 \\
\hline Aug 23, 2013 & Tripoli & Two mosques & Two car bombs & 42 & 400 \\
\hline Nov 19, 2013 & Suburb, South Beirut & Iranian Cultural Center & $\begin{array}{l}\text { Car bomb and explosive } \\
\text { motorcycle }\end{array}$ & 22 & 146 \\
\hline $\operatorname{Dec} 3,2013$ & Beirut & $\begin{array}{l}\text { Hassan Lakkis, senior Hezbollah } \\
\text { commander }\end{array}$ & $\begin{array}{l}\text { Assassination by two } \\
\text { gunmen }\end{array}$ & 1 & 0 \\
\hline Dec 27, 2013 & Downtown, Beirut & Former Minister Mohamad Chatah & Car bomb & 6 & 70 \\
\hline Jan 2, 2014 & Haret Hreik, South Beirut & Hezbollah Political Office & Car bomb & 4 & 77 \\
\hline Jan 16,2014 & Hermel & Bustling neighborhood & Car bomb & 5 & 42 \\
\hline Jan 2I, 2014 & Haret Hreik, South Beirut & Bustling street & Suicide bomber & 4 & 46 \\
\hline Feb I, 2014 & Hermel & Petrol station & Car bomb & 4 & 23 \\
\hline Feb 3, 2014 & South Beirut & Van & Suicide bomber & 0 & 2 \\
\hline Feb 19,2014 & Suburb, South Beirut & Iranian Cultural Center & Two car bombs & 8 & 128 \\
\hline Feb 22,2014 & Hermel & Army Post & Car bomb & 5 & 17 \\
\hline March 29, 2014 & Arsal & Army soldiers & Car bomb & 3 & 4 \\
\hline June 20,2014 & Dahr Al Baidar & Police checkpoint & Suicide bomber & 1 & 32 \\
\hline June 24,2014 & Beirut & Military checkpoint & Car bomb & 0 & 12 \\
\hline June 27,2014 & Beirut & Hotel & Suicide bomber & 0 & 11 \\
\hline Aug 6, 2014 & Tripoli & Army checkpoint & Homemade bomb & 1 & 10 \\
\hline Sept 19,2014 & Arsal & Army & Bomb & 2 & 3 \\
\hline Sept 20, 2014 & Eastern Borders of Lebanon & Hezbollah checkpoint & Bomb & 2 & 0 \\
\hline Nov 14,2014 & Arsal & Army & Bomb & 0 & 3 \\
\hline Dec 3, 2014 & Arsal & Army & Bomb & I & 2 \\
\hline Jan 10,2015 & Tripoli & Café & Suicide bomber & 9 & 30 \\
\hline Jan 26, 2015 & Zagharta & Ghassan Ajaj, ISF intelligence officer & Gunman & I & 0 \\
\hline March 2, 2015 & North Lebanon & Bader Eid, brother of Alawite leader Ali Eid & Gunman & I & 0 \\
\hline Nov 5, 2015 & Arsal & Qalamoun Muslim Scholars Committee & Motorcycle bomb & 5 & 15 \\
\hline Nov 6, 2015 & Arsal & Army & Improvised explosive device & 0 & 5 \\
\hline \multirow[t]{2}{*}{ Nov 12,2015} & Bourj el-Barajmeh, South Beirut & Hezbollah stronghold & Two suicide bombers & 43 & 240 \\
\hline & & & & 205 & 1796 \\
\hline
\end{tabular}

Note: Adapted from National Consortium for the Study of Terrorism and Responses to Terrorism (START). (2013). Global Terrorism Database [Data file]. Retrieved from http://www.start.umd.edu/gtd. ${ }^{19}$

Abbreviation : ISF, Internal Security Forces.

women. As the majority of Syrians are low- to semiskilled laborers and $92 \%$ of them are working without contracts, the work available to the most vulnerable of them is heavily underpaid, intermittent, and outside of Lebanese labor protection mechanisms, aggravating their poor condition and inability to meet their fundamental household expenses. ${ }^{5}$ Moreover, a recent assessment showed that $30 \%$ of Syrian households lack sufficient water for domestic use, $15 \%$ are deficient in hygiene items, and $40 \%$ cannot access appropriate latrines. ${ }^{8}$

The number of displaced Syrian children in Lebanon who are not receiving education is nearly two-thirds and is equal to 300,000 in spite of great attempts to register 90,000 in the year 2013-2014, and only one-third of them leave their homes once every week contributing to sadness and feelings of isolation. Also, one in ten displaced Syrian children are forced to work to complement family income and others are subjected to child marriage, drugs and alcohol abuse, violent groups, ${ }^{5}$ and begging. ${ }^{8}$ Furthermore, the 2013-2014 report of the Lebanon Millennium Development Goals showed that many of the interviewed Syrian displaced families report living on one cooked meal per day - including $45 \%$ of Palestine refugees from Syria- and only $20 \%$ have three. Just $6 \%$ of the displaced children from Syria aged 6-23 months eat the minimum sufficient diet based on the United Nations Children's Fund (UNICEF)/WHO standards. ${ }^{5}$ Marriages within the family has led to an increase in the rates of abortions and child malformations. ${ }^{17}$ Refugees' health is worsening ${ }^{15}$ with $\sim 11 \%$ of the displaced Syrians exhibiting psychiatric symptoms, ${ }^{20}$ specifically psychological scars of mischievous experiences of sexual and sex-based violence as well as physical assaults - frequently within the family - and emotional violence. While cases are broadly underreported, $25 \%$ of the reported incidents using protection mechanisms show that $87 \%$ of the identified and assisted were women and girls while 13\% were men and boys. ${ }^{5}$ In addition, 2013 
information fathered by the Amel Association revealed that of the Syrian patients assessed, 47\% suffered from skin diseases (lice, staphylococcal skin infection, leishmaniasis), $27 \%$ had diseases of the digestive system, and $19 \%$ suffered from respiratory diseases. ${ }^{21}$

\section{Discussion}

Since the beginning of the refugee influx to Lebanon, a highly indebted middle-income country with a history of political strife, presence of other vulnerable displaced populations, and weak government capacities, ${ }^{2}$ as well as standing political deadlock, ${ }^{22}$ the conflict dissolved into a mutual and precarious crisis for both displaced Syrians and the Lebanese as they shared the scrambled soup of aggravating hardships of the mass influx to a previously stressed state.

Both populations are struggling from economic and security impacts, be it poor living conditions or life-threatening events, increasing the tension between formerly harmonious neighbors. Lebanon has neither been able to mitigate nor respond to this high-impact and vigorous disaster, acting as a weak host state to displaced Syrians and with incapable body of governors for its citizens. With the 3RP and its Lebanese chapter (the LCRP) representing a comprehensive theoretical strategy for the diverse response sectors, their successful application and efficacy remain questionable taking into account the highly elevated needs compared with the persistent underfunding as well as the absence of sustainability in the various projects implemented in Lebanon at the local, national, or international level.

It is crucial to acknowledge that this paper includes limitations as a result of the unstable structure of the Syrian refugee crisis in Lebanon. First, the majority of evidence about this emergency comes from gray literature and reports from national and international organizations, and not from journal articles with peer reviews. Second, the evidence used was based on a scoping review of the literature rather than a comprehensive one. Third, statistics presented about refugees may only be accurate for a short duration of time, as their condition is largely unstable and their numbers in Lebanon are continuously increasing.

\section{Conclusion}

Based on the information compiled from different resources regarding funding deficiency for this and other crises and the inferior economic situation, there are two major recommendations to alleviate the current and future human suffering in Lebanon. First, continuous and effective monitoring and follow-up of local, national, and regional development, and economic projects should be ensured to build back better. Most of the projects initiated in Lebanon have a strong onset but tend to be neglected and forgotten as time passes. While trying to gather information for this report, websites of such projects were found outdated and the projects themselves had not been fully implemented. Hence, it is crucial for national or international donors to perform continuous evaluation and application of their funded programs; otherwise, the funds are wasted attempts with no significant progress. Second, the provision of good-quality and accountable humanitarian aid should be carried out ensuring its sustainability. One of the key problems of the aid given to Syrian refugees and poor Lebanese in Lebanon is its frequent abruption due to lack of funding. When financial resources are available, they are used to directly provide immediate needs to the affected populations, contributing to their dependency and not using their inherent capacities. When they are lacking, however, those vulnerable individuals are left alone to face hardships and agony. Therefore, future assistance should be administered taking into account the "do no harm" principle, by which more efficient use of monetary resources could be executed. Finally, publishing of research articles examining the resilience and coping strategies undertaken in Lebanon as well as the humanitarian response setbacks is crucial in order to respond better in future crisis in Lebanon and worldwide.

\section{Author contributions}

All authors contributed toward data analysis, drafting and critically revising the paper and agree to be accountable for all aspects of the work.

\section{Disclosure}

The authors report no conflicts of interest in this work.

\section{References}

1. UNDP. About Lebanon. 2015. UNDP; 2013. Available from: http:// www.lb.undp.org/content/lebanon/en/home/countryinfo/. Accessed December 1, 2015.

2. Country Cooperation Strategy for WHO and Lebanon 2010-2015. Country Cooperation Strategy. Cairo: World Health Organization; 2010:15-18

3. PreventionWeb. Basic Country Statistics and Indicators (2014). Available from: http://www.preventionweb.net/countries/jpn/data/. Accessed December 1, 2015

4. Refugee Response in Lebanon Briefing Documents: UNHCR; 2015. Available from: http://www.europarl.europa.eu/meetdocs/2014_2019/ documents/droi/dv/95_finalbriefingkit_/95_finalbriefingkit_en.pdf. Accessed December 1, 2015.

5. United Nations. Lebanon Crisis Response Plan 2015-2016. United Nations; 2014. Available from: http://reliefweb.int/sites/reliefweb.int/files/ resources/2015-2016_Lebanon_CRP_EN.pdf. Accessed December 1, 2015.

6. UNHCR. Syria Regional Refugee Response. 2015. UNHCR; 2015 Available from: http://data.unhcr.org/syrianrefugees/country.php? id=122. Accessed December 1, 2015. 
7. UNHCR, UNDP. Lebanon. 2015. UNHCR, UNDP; 2014. Available from: http://www.3rpsyriacrisis.org/the-3rp/lebanon/. Accessed December 1, 2015.

8. UNHCR. Independent Program Evaluation of UNHCR's Response to the Refugee Influx in Lebanon and Jordan. Brussels, Belgium: UNHCR; 2015. Available from: http://www.unhcr.org/research/ evalreports/5551f5c59/independent-programme-evaluation-ipe-unhcrsresponse-refugee-influx-lebanon.html. Accessed December 1, 2015.

9. El-Jardali F, Hammoud R, Fouad F, Bou Karoum L. K2P Briefing Note. Promoting Access to Essential Health Care Services for Syrian Refugees in Lebanon. Beirut, Lebanon: Knowledge to Policy (K2P) Center; 2014. Available from: https://www.aub.edu.lb/k2p/products/Documents/ Revised_K2P\%20Briefing\%20Note_Syrian\%20Refugees-2014-06-11. pdf. Accessed December 1, 2015.

10. UNHCR. United Nations High Commissioner For Refugees, Middle East \& North Africa (UNHCR MENA). 2015. UNHCR; 2015. Available from: http://data.unhcr.org/syrianrefugees/partner.php?OrgId=49. Accessed December 1, 2015.

11. [No authors listed]. Syrian refugees seeking help. Lancet. 2015;385:202.

12. Holmes D. Chronic disease care crisis for Lebanon's Syrian refugees. Lancet Diabetes Endocrinol. 2014;3(2):102.

13. Session on October 23, 2014. Prime Minister Council, Beirut. Available from: http://www.pcm.gov.lb/arabic/subpg.aspx?pageid=6118. Accessed November 1, 2015. Arabic.

14. Syria Regional Refugee Response. Inter-agency Information Sharing Portal. Available from: http://data.unhcr.org/syrianrefugees/regional.php. Accessed June 1, 2016.
15. Coutts A, Fouad F, Batniji R. Assessing the Syrian health crisis: the case of Lebanon. Lancet. 2013;381(9875):e9.

16. Zetter R, Ruaudel H, Deardorff-Miller S, Lyytinen E, Thibos C, Pedersen F. The Syrian Displacement Crisis and a Regional Development and Protection Programme: Mapping and Meta-Analysis of Existing Studies of Costs, Impacts and Protection. Denmark: Refugee Studies Centre, Oxford Department of International Development, University of Oxford; 2014.

17. Cousins S. Syrian crisis: health experts say more can be done. Lancet. 2015; 385(9972):931-934.

18. Christophersen M, Liu J, Thorleifsson CM, Tiltnes AA. Lebanese Attitudes Towards Syrian Refugees and the Syrian Crisis: Results from a National Opinion Poll. Lebanon: ALNAP; 2013.

19. National Consortium for the Study of Terrorism and Responses to Terrorism (START). (2013). Global Terrorism Database [Data file]. Available from: https://www.start.umd.edu/gtd/search/Results.aspx?country=110. Accessed June 7, 2016.

20. Akoury-Dirani L, Sahakian TS, Hassan FY, Hajjar RV, Asmar KE. Psychological first aid training for Lebanese field workers in the emergency context of the Syrian refugees in Lebanon. Psychol Trauma. 2015;7(6):533-538.

21. Refaat M, Mohanna K. Syrian refugees in Lebanon: facts and solutions. Lancet. 2013;382(9894):763-764.

22. The Economist. 546 days without a president. Beirut; 2015 [December 5]. Available from: http://www.economist.com/news/middle-east-andafrica/21679507-multiple-crises-tiny-country-546-days-withoutpresident. Accessed December 30, 2015.
Risk Management and Healthcare Policy

\section{Publish your work in this journal}

Risk Management and Healthcare Policy is an international, peer-reviewed, open access journal focusing on all aspects of public health, policy, and preventative measures to promote good health and improve morbidity and mortality in the population. The journal welcomes submitted papers covering original research, basic science, clinical and epidemiological

\section{Dovepress}

studies, reviews and evaluations, guidelines, expert opinion and commentary, case reports and extended reports. The manuscript management system is completely online and includes a very quick and fair peerreview system, which is all easy to use. Visit http://www.dovepress.com/ testimonials.php to read real quotes from published authors. 